\title{
Feed substrates influence biofilm formation on reverse osmosis membranes and their cleaning efficiency
}

\author{
Sowmya Marka ${ }^{1}$ and Sanjeev Anand ${ }^{2}$ \\ Midwest Dairy Foods Research Center, Dairy and Food Science Department, South Dakota State University, Brookings 57007
}

\begin{abstract}
The dairy industry is increasingly using reverse osmosis (RO) membranes for concentration of various fluid feed materials such as whey and ultrafiltration (UF) permeate. This study compared the effect of UF permeate and whey on membrane biofilm formation. A Bacillus sp., previously isolated in our laboratory from a cleaning-resistant membrane biofilm, was used to develop 48-h-old static biofilms on RO membrane pieces, using the different feed substrates (UF permeate, whey, and an alternating whey/UF feed). Biofilms were analyzed for viable counts by the swab technique, and we used scanning electron and atomic force microscopy for microstructure imaging. The membrane cleaning process included 6 sequential steps. We observed differences in the resistance pattern of the 3 types of biofilms to the typical cleaning process. The mean pretreatment counts of the 48-h UF permeate biofilms were $5.39 \mathrm{log}$ $\mathrm{cfu} / \mathrm{cm}^{2}$, much higher than the whey biofilm counts of $3.44 \mathrm{log}$, and alternating whey/UF biofilm counts of $4.54 \mathrm{log}$. After a 6-step cleaning cycle, we found 2.54 log survivors of the Bacillus isolate on UF biofilms, whereas only $1.82 \log$ survivors were found in whey biofilm, and $2.14 \mathrm{log}$ survivors on whey/UF permeate biofilms. In conclusion, the UF permeate biofilms was more resistant to the biofilm cleaning process compared with the whey or whey/UF permeate biofilms. Scanning electron micrographs showed different microstructures of biofilms based on the type of feed. For UF permeate and whey/UF permeate biofilms, bacilli were present in multilayers of cells in aggregates or irregular clusters with foulant layers. In contrast, those in whey biofilms were in monolayers, with a smoother, flatter appearance. Atomic force microscopy analysis indicated that UF permeate biofilms had the greatest surface roughness among the biofilms, reflecting intensified bacterial colonization. The biofilm micro- and nanostructure variations for the 2 feed substrates and their combina-
\end{abstract}

Received May 29, 2017.

Accepted September 4, 2017.

${ }^{1}$ Current affiliation: Laura Chenel's Chevre, Sonoma, CA 95476.

${ }^{2}$ Corresponding author: Sanjeev.Anand@sdstate.edu tion may have resulted in differences in their resistance to the cleaning process.

Key words: biofilm, whey, ultrafiltration permeate, cleaning, reverse osmosis membrane

\section{INTRODUCTION}

In the dairy manufacturing industry, membrane technology is an enduring, increasing, and abundantly used separation method, especially for its unique high selectivity based separation mechanism based on the pore size (Bereschenko et al., 2010, Lipnizki, 2010). It has also emerged as an important nonthermal process with an uncomplicated operation that does not result in any phase change (Madaeni and Samieirad, 2010). Reverse osmosis (RO) is one process of membrane technology that finds many applications in the dairy industry such as concentration, demineralization, and salt removal, in addition to fractionation of whey, ultrafiltration (UF) permeate, milk, and butter milk (Madaeni and Mansourpanah, 2004). Retentate and permeate from membrane separation techniques are important starting materials in producing valuable ingredients with unique functional properties, excellent nutritional value materials such as whey protein isolates, lactose, and biologically stable high-purity reclaimed water (Pabby et al., 2008). In the dairy industry, RO is most common membrane technology for whey and UF permeate to recover the valuable lactose, proteins, and salts for economic and environmental benefits.

The composition of dairy feed substrates is complex, consisting of different concentrations of proteins, carbohydrates (e.g., lactose), lipids (e.g., phospholipids), minerals, nonprotein $\mathrm{N}$ compounds, citric and lactic acids, and microorganisms. Fouling by such feed substrates in filtration elements results in films characterized by initial layers of changing composition. All of these films are extraneous to the microorganisms that become attached to the fouled layers by means of additional extracellular polymeric secretions and lead to development of biofilms on membranes (Lund et al., 1985). Current filtration membrane units, especially RO membranes, encounter biofouling issues, which impair their performance and strongly affect plant productivity. Problems 
are mainly due to plugging of a membrane's pores by the biofilm, which obstructs the feed concentrate route. Biofilm development results in an increase of differential pressures, continued flux decline, increased power needs, and diminished product quality. Once in process, biofouling continually and intensively hinders the RO filtration process. Additionally, the construction of "spiral-wound" membrane units, spacers between the membranes, additional inner surfaces, roughness of the membrane surface, and processing conditions also make these membranes susceptible to microbial attachment, leading to the formation of biofilm layers (Bereschenko et al., 2008, 2010).

Various types of fouling have been observed on RO membranes, such as organic, particulate or colloidal, inorganic (scaling), and biofouling (microbial/biological). Fouling by inorganic or organic foulants and microorganisms can occur together, and these constituents can interact in terms of function (Nguyen et al., 2012). A range of constituents and microbes are involved in the evolution of these surface-adhered complex morphologies after an extended run of a typical RO process, which is primarily based on the type of feed materials processed and amount of contaminants in the feed (Bereschenko et al., 2010). Therefore, to retain the penetrability and selectivity of the membranes, frequent cleaning and disinfection sequences are needed that can remove foulants and microorganisms (Tang et al., 2010). The physical and microbiological processes correlated with biofilm development under these tremendous pressure and dynamic settings are not clearly known (Bereschenko et al., 2008). In previous work in our laboratory, the effect of cleaning resistance pattern on membrane biofouling was studied with a single type of feed substrate (Hassan et al., 2010; Anand and Singh, 2013). In addition, biofilm formation can vary with changes in the types of feed material, especially when alternating whey and UF permeate streams through the same filtration system, which may lead to "gooey" layers of foulants. In view of this, the current study was undertaken to understand and characterize membrane biofouling under different feed substrates. We hypothesized that feed substrates such as cheese whey, skim milk UF permeate, and their alternating combination (as practiced by some cheese plants) would cause variations in biofilm microstructures and result in differences in the resistance of the biofilms to a typical clean-in-place (CIP) membrane cleaning protocol.

\section{MATERIALS AND METHODS}

\section{Source and Propagation of the Culture Isolate}

The Bacillus sp. used throughout this study was originally isolated during a previous study (Anand and
Singh, 2013) in our laboratory from a 10-mo-old RO membrane obtained from a commercial cheese manufacturer. The isolate was identified using biotyping at a diagnostic laboratory (Veterinary Science Department, South Dakota State University, Brookings). This Bacillus sp. formed the most resistant biofilms among 26 biofilm isolates of 10 different genera, isolated from 2to 14-mo-old whey RO membranes (Anand and Singh, 2013). The isolate was stored in cryovials at $-80^{\circ} \mathrm{C}$ in a deep freezer (Nuaire, Plymouth, MN). The culture isolate was activated in brain-heart infusion (BHI) broth by incubating a single bead from the stock cryovials, followed by streaking on plate count agar (Difco, Franklin Lakes, NJ). The plate was incubated under aerobic conditions at $35^{\circ} \mathrm{C}$ for $18 \mathrm{~h}$. After $18 \mathrm{~h}$, a single colony was picked and transferred to a $10-\mathrm{mL}$ BHI broth tube. The inoculated broth was incubated at $35^{\circ} \mathrm{C}$ for 8 to 12 $\mathrm{h}$ to obtain activated cells in their logarithmic phase and was used to inoculate each type of feed substrate.

\section{Membrane Preparations for Biofilm Formation Under Laboratory Conditions}

An unused, net-wrapped, spiral-wound element with cross-linked fully aromatic polyamide composite RO membrane was purchased from a membrane manufacturer (TRO 3838, Toray Membrane USA, Poway, $\mathrm{CA}$ ). These membranes have a polysulfone support layer, which is cast onto a nonwoven polyester fabric. Polyamide composite membranes have a wide $\mathrm{pH}$ tolerance $(2.5$ to 10.5$)$, low thermal stability $\left(50^{\circ} \mathrm{C}\right)$, and are prone to oxidative degradation by free chlorine. This spiral-wound membrane was cut into $10-\mathrm{cm}^{2}$ slices using an electric cutter (powered handsaw, Black and Decker, Towson, MD). Aseptic conditions were maintained throughout this process and the membrane pieces were preserved under refrigeration in $2 \%$ sodium meta-bisulfite, as recommended by the manufacturer. From the $10-\mathrm{cm}^{2}$ slices, 14 membrane pieces of $2 \mathrm{~cm}^{2}$ were cut for further use to develop biofilms under static conditions. The setup for biofilm formation was similar to that standardized in a previous study in our laboratory (Anand and Singh, 2013).

\section{Types of Feed Substrates}

Two feed substrates and a combination thereof were used as growth substrates to form 3 types of biofilms. Full-fat cheese whey and skim milk UF permeate were obtained from a commercial cheese plant. Both feed substrates were stored at $-20^{\circ} \mathrm{C}$ until further use. The substrates were thawed under refrigeration and sterilized using a vacuum-driven disposable filtration system 
with a $0.22-\mu \mathrm{m}$ pore size (Stericup; Millipore Corp., Billerica, MA) before use.

\section{Biofilm Development on Membrane Pieces}

Membrane pieces, sanitized with $0.5 \%$ hydrogen peroxide, were kept side by side, without any overlaps, inside a petri dish $\left(150 \times 50 \mathrm{~mm}^{2}\right)$ in an arranged manner, with the retentate side facing upwards. The membrane pieces were submerged in $70 \mathrm{~mL}$ of sterile feed substrate, inoculated with $1 \%$ of activated Bacillus inoculum $(7 \log \mathrm{cfu} / \mathrm{mL})$. The incubation was carried out under static conditions at $35^{\circ} \mathrm{C}$ for 24 and $48 \mathrm{~h}$ for the development of single species-resistant biofilms. This laboratory-based resistant biofilm development was based on our previous work (Anand and Singh, 2013). Based on the nature of the substrate, 3 types of biofilms were formed: (1) whey biofilms, (2) UF permeate biofilms, and (3) whey/UF permeate biofilms. In the latter case, whey was used as a feed substrate for first $24 \mathrm{~h}$, followed by UF permeate as substrate for the next $24 \mathrm{~h}$; the order of feed substrate was based on the actual process followed in the cheese plant, where whey was the major filtration feed and UF permeate was filtered only intermittently using RO membranes.

\section{Enumeration of Biofilm-Embedded Bacteria as a Measure of Membrane Biofouling}

The swab technique was applied to obtain viable counts from membrane biofilms. Two nonabsorbent sterile cotton swabs were used for each membrane (Yang et al., 2005). Biofilm swabbing was done only on the retentate side in 4 directions: top to bottom, left to right, diagonally upwards, and diagonally downwards (Siegerman et al., 2006). Swabbing was always performed using the same technique. After swabbing, the swab was broken and placed in a $10-\mathrm{mL}$ tube with PBS (Asséré et al., 2008). The tubes were vortexed for $60 \mathrm{~s}$ before plating on plate count agar. These plates were incubated for 24 to $48 \mathrm{~h}$ at $35^{\circ} \mathrm{C}$ and the counts are reported as colony-forming units per milliliter.

\section{Membrane Cleaning Trials}

Cleaning resistance of the Bacillus sp. embedded within different biofilms was evaluated against a typical 6-step CIP protocol as described by Anand and Singh (2013). After biofilms were generated on the membrane surfaces, the fouled membranes were rinsed with distilled water to remove loosely attached cells and any foulants from the surface of membrane. Two membrane pieces $\left(2 \mathrm{~cm}^{2}\right)$ were randomly picked and set aside for pre-treatment counts. The remaining 12 membrane pieces, with biofilms, were cleaned using the CIP protocol, which included the following steps: alkali, surfactant, acid, enzyme, a second surfactant, and sanitizer (Anand and Singh, 2013). The stock CIP chemical solutions were made fresh by diluting each concentrated chemical in distilled water and increasing the temperature to $50^{\circ} \mathrm{C}$ (except for sanitizer chemical) to keep the ratio and $\mathrm{pH}$ as per the mentioned CIP procedure. The biofilms on the membrane pieces were treated with steps 1 to 6 sequentially. To evaluate the efficiency of cleaning, 2 membrane pieces were removed after each step, rinsed with sterile water, and soaked in cold neutralizing broth for 10 min before being swabbed for enumeration of viable cells (post-treatment counts). A similar procedure was adopted to test the remaining 10 membrane pieces after each of the remaining steps of the 6-step CIP. Post-treatment and pre-treatment counts were compared to determine the reduction in counts due to the CIP process. All experiments were conducted in replicates of 3 .

\section{Microscopic Observations of Membrane Biofilms}

Surface topography of unused and fouled membranes on the retentate side was imaged using scanning electron microscopy and atomic force microscopy (AFM). To minimize structural damage to the biofilms, a modified air-drying method was used to obtain a partially dehydrated biofilm for microscopy. After gentle rinsing with phosphate buffer ( $\mathrm{pH} 7.0$ ), membrane pieces (2$\mathrm{cm}^{2}$ pieces with laboratory-grown biofilms) were airdried at $22^{\circ} \mathrm{C}$ under laminar air flow for $24 \mathrm{~h}$ (Hassan et al., 2010). Unused (new) membrane pieces were also rinsed and air-dried before imaging. Three trials in total were conducted for each of the experiments, using 3 to 4 pieces of membrane in each trial. For scanning electron microscopy, the biofilm samples on membrane pieces were sputter-coated with a 5-nm layer of gold using a CRC-150 sputtering system (Plasma Science Inc., Lorton, VA). About 10 to 15 visual scan areas of the specimens were observed with a Hitachi scanning electron microscope (model S-3400N, Hitachi SCI Systems Ltd., Tokyo, Japan) at 5 to $10 \mathrm{kV}$. Representative images are presented in the Results and Discussion section.

For the AFM studies, no pre-treatment was required for samples. All observations were made using a commercial Agilent 5500 scanning probe microscope. The imaging was done in tapping mode using Si cantilevers (Budget Sensors TAP $300 \mathrm{Al}$; Innovative Solutions Bulgaria Ltd., Sofia, Bulgaria) with the AFM tip having resonant frequency around $300 \mathrm{kHz}$ (Venkatesan et 
al., 2014). The membrane sample was mounted on the sample stage by sticking 4 corners of the membrane to the stage with scotch tape. The scanner was positioned at the flat center of the sample surface. The tip oscillation frequency was set $200 \mathrm{~Hz}$ above the resonance frequency to image in net attractive regimen. Samples were scanned at a moderate scan rate of 0.3 to $0.6 \mathrm{~Hz}$ to decrease the effect of structural damage; imaging resolution was $512 \times 512$ pixels. All images were stored in ASCII format and Gwyddion software (http:// gwyddion.net/) was used to process the images in 2and 3-dimensional (2D and 3D) format and to measure the skewness and surface roughness for assessing the variation in the membrane morphology subject to different feed substrates.

Quantitative analysis on images was done on 2 parameters: root mean square ( $\mathbf{S}_{\mathrm{q}}$ or RMS; roughness) and surface skewness $\left(\mathbf{S}_{\mathrm{sk}}\right)$. The $\mathrm{S}_{\mathrm{q}}$ represents the standard deviation of surface heights to describe the accuracy of the surface compared with a fully smooth surface. The $\mathrm{S}_{\mathrm{sk}}$ represents profile symmetry relative to mean line and helps to calculate the extent of surface texture regularity through the distribution of peaks rather than valleys on membrane. The $\mathrm{S}_{\mathrm{sk}}$ value is zero when the height distribution is symmetrical, positive when the height distribution is asymmetrical with more peaks than valleys, and negative when the valleys are prevalent and the surface is too planar (Raposo et al., 2007; Zaky et al., 2012).

At least 3 scans were performed on each membrane sample to observe changes in biofilm microstructure and arrangement of embedded cells on the membrane surfaces. Three trials were conducted for each experiment, with 3 pieces of membrane in each trial.

\section{Statistical Analysis}

Each mean and standard deviation was calculated from counts of 3 identical tested membrane samples with 2 replicates. All the data were analyzed using ANOVA with BioStat 5.3 software (AnalystSoft Inc., Walnut, CA), and the Tukey test (one-way ANOVA) was used to compare the means. Differences in all experiments were considered significant at $P<0.05$.

\section{RESULTS AND DISCUSSION}

\section{Comparison of Viable Counts in 24- and 48-Hour-Old Biofilms}

All biofilms consist of small communities of microbial cells enclosed in a matrix of extracellular polymeric substance. Variations in biofilm morphology result from several factors such as nutrient availability, type of microorganisms that enclose the biofilm, hydrodynamic conditions, and feed particle interactions with nonmicrobial components from the environment (Donlan, 2002). In the present study, we compared the effect of different feed substrates on biofilm development on RO membranes. All other factors or conditions (i.e., bacterial strain, initial inoculation rate, incubation time, and temperature) were kept constant. A Bacillus sp. that was isolated during a previous study in our laboratory and that showed resistance to CIP chemicals (Anand and Singh, 2013) was chosen for this study to form resistant biofilms under static conditions. The development of biofilms increased with incubation time from 24 to $48 \mathrm{~h}$. This was evident by the pre-treatment viable counts of 48-h-old biofilms that were $\sim 1 \log$ higher than those of the 24-h-old biofilms. Previous researchers have found a similar increase in biofilm formation with increased duration of incubation from 12 to $24 \mathrm{~h}$ (Anand and Singh, 2013). The expression of genes associated with quorum sensing has been shown to be elevated with time (González and Keshavan, 2006; Lu et al., 2013). These results could imply that the biofilms advance from reversible to irreversible adsorption with time and develop into a mature state, expressing phenotypic changes (Rice et al., 2000). Pre-treatment viable counts at 24 and $48 \mathrm{~h}$ of all 3 types of biofilm are presented in Table 1. In all cases, the feed substrate inoculation was 7 logs per $\mathrm{mL}$, and the UF permeate-fouled membrane biofilm counts were 4.52 and $5.39 \log _{10} \mathrm{cfu} / \mathrm{cm}^{2}$ after 24 and $48 \mathrm{~h}$ of incubation, respectively. This increase in the biofilm counts may be attributed to UF permeate feed characteristics, $\mathrm{pH}$, nutrient level, presence of multivalent cations, and ionic strength. The $\mathrm{pH}$ of $\mathrm{UF}$ permeate is generally around 6.5 , with negligible protein content and higher lactose and mineral contents. (Robinson, 1986). The whey-fouled membrane counts were 2.69 and $3.44 \operatorname{logs}$, the lowest of the 3 types of biofilm, at 24 and $48 \mathrm{~h}$, respectively. The whey biofilms, in general, showed counts about 2.0 logs lower than the UF permeate biofilms. In terms of composition, Cheddar cheese whey generally has a higher protein content, including whey proteins, and lactic acid compared with UF permeate (De Wit, 2001; Tsakali et al., 2010). These variations in composition may have led to quantitative differences in biofilm development under these 2 feed substrates. The alternating whey/UF permeate-treated biofilms had log counts of 3.75 and 4.54 at 24 and $48 \mathrm{~h}$, respectively. The alternating whey/UF permeate biofilms had intermediate counts compared with the other biofilms. This may be because the whey and UF permeate substrates were alternated for $24 \mathrm{~h}$ each, which changed the biofilm formation because of 
Table 1. Total viable counts $\left(\log _{10} \mathrm{cfu} / \mathrm{cm}^{2}\right)$ in 24 - and 48 -h-old Bacillus sp. biofilms on reverse osmosis membranes ${ }^{1}$

\begin{tabular}{lccc}
\hline Incubation at $35^{\circ} \mathrm{C}$ & $\mathrm{UF}$ & Whey & Whey/UF \\
\hline $24 \mathrm{~h}$ & $4.52 \pm 0.21^{\mathrm{A}, \mathrm{a}}$ & $2.69 \pm 0.10^{\mathrm{A}, \mathrm{c}}$ & $3.75 \pm 0.19^{\mathrm{A}, \mathrm{b}}$ \\
$48 \mathrm{~h}$ & $5.39 \pm 0.31^{\mathrm{B}, \mathrm{a}}$ & $3.44 \pm 0.08^{\mathrm{B}, \mathrm{c}}$ & $4.54 \pm 0.14^{\mathrm{B}, \mathrm{b}}$ \\
\hline
\end{tabular}

$\overline{\mathrm{A}, \mathrm{B}}$ Means within a column for individual consortia not sharing common superscript letters are significantly different $(P<0.05)$.

${ }^{\mathrm{a}-\mathrm{c}}$ Means within a row not sharing common superscript letters are significantly different $(P<0.05)$.

${ }^{1}$ Mean $\pm \mathrm{SD}$ of 3 replicates. Membranes were subjected to reverse osmosis using feed substrates of UF permeate, whey permeate, or alternating whey/UF permeate.

different nutrients and interactions in the residues of 2 substrates. More studies need to be conducted to understand biofilm formation under alternating feeds and industrial conditions.

\section{Biofilm Cleaning Studies}

We compared the ease of cleaning of 3 types of biofilms by performing a standard 6-step CIP cycle against all 48-h-old biofilms under static conditions. These in vitro biofilms, with initial counts of 3.44 to 5.39 logs, were treated with the cleaning chemicals sequentially. After every treatment step, we assessed post-treatment counts of surviving bacteria for each feed substrate biofilm and were statistically analyzed (Table 2).

It may be seen from the results that the final sanitizer treatment in the sequential CIP cycle resulted in a reduction to 2.54 logs. This revealed the survivability of biofilm-embedded bacterial cells even after completion of the existing CIP protocol.

The other 2 types of biofilms were subjected to the sequential CIP process. Minimum survival to $1.82 \operatorname{logs}$ from 3.44 logs, resulted for whey biofilm, whereas an intermediate reduction to $2.14 \operatorname{logs}$, from $4.54 \operatorname{logs}$, resulted for the alternating whey/UF biofilm. Further CIP steps resulted in lower counts to 1.91, 1.87, and $1.82 \operatorname{logs}$ in the next 3 steps, respectively. Overall, the alternating whey/UF permeate biofilms showed a lower survival after the enzyme step compared with the other 2 biofilms. As substantial reductions were not observed after the acid treatment (step 3), the relative ineffectiveness of the later steps was quite evident. Based on the above results, there is scope to modify the enzymebased cleaning step, which may help to destabilize the biofilm matrix, after which the sanitizer step could be more effective (Anand and Singh, 2013).

After all 6 steps of the CIP protocol, the highest post-treatment counts were found in the UF-fouled biofilms at $2.54 \operatorname{logs}$, whereas the alternating whey/ UF permeate and whey biofilms showed slightly lower $\log$ survivors at 2.14 and $1.82 \operatorname{logs}$, respectively. Based on these studies, the UF permeate biofilms were most difficult to clean, as they resulted in the highest counts after cleaning, despite the fact that the initial spiking level for all feed substrates was the same $(7.0 \operatorname{logs} / \mathrm{mL})$. The possible reasons for the higher survivors within UF biofilms after the CIP protocol may be the better availability of nutrients for biofilm-embedded bacteria and their better protection due to its unique multilayered microstructure.

\section{Scanning Electron Microscopy of Biofilms}

Scanning electron microscopy was used to assess the qualitative development of the biofouling layers under different feed substrates and to understand their microstructures. Clear differences were observed in the microstructure of biofilms developed using UF permeate, whey, and alternating whey/UF permeate feed substrates (Figure 1B, C, and D). For comparison with the biofouled membranes, a virgin membrane

Table 2. Membrane biofilm counts $\left(\log _{10} \mathrm{cfu} / \mathrm{cm}^{2}\right)$ under different feed substrates ${ }^{1}$ of 48 -h-old Bacillus sp. biofilms by sequential application of clean-in-place (CIP) chemicals under static conditions

\begin{tabular}{|c|c|c|c|}
\hline CIP process step & UF & Whey & Whey/UF \\
\hline Pre-treatment count & $5.39 \pm 0.31^{\mathrm{a}}$ & $3.44 \pm 0.08^{\mathrm{c}}$ & $4.54 \pm 0.14^{\mathrm{b}}$ \\
\hline \multicolumn{4}{|l|}{ Post-treatment count } \\
\hline After step 1: Alkali & $3.81 \pm 0.14^{\mathrm{A}, \mathrm{a}}$ & $2.47 \pm 0.07^{\mathrm{A}, \mathrm{b}}$ & $3.43 \pm 0.11^{\mathrm{A}, \mathrm{a}}$ \\
\hline After step 2: Surfactant 1 & $3.31 \pm 1.08^{\mathrm{B}, \mathrm{a}}$ & $2.36 \pm 0.07^{\mathrm{A}, \mathrm{b}}$ & $3.23 \pm 0.10^{\mathrm{A}, \mathrm{a}}$ \\
\hline After step 3: Acid & $2.71 \pm 0.06^{\mathrm{C}, \mathrm{a}}$ & $1.95 \pm 0.12^{\mathrm{B}, \mathrm{b}}$ & $2.83 \pm 0.16^{\mathrm{B}, \mathrm{a}}$ \\
\hline After step 4: Enzyme & $2.67 \pm 0.04^{\mathrm{C}, \mathrm{a}}$ & $1.91 \pm 0.11^{\mathrm{B}, \mathrm{b}}$ & $2.30 \pm 0.14^{\mathrm{C}, \mathrm{ab}}$ \\
\hline After step 5: Surfactant 2 & $2.61 \pm 0.09^{\mathrm{C}, \mathrm{a}}$ & $1.87 \pm 0.13^{\mathrm{B}, \mathrm{b}}$ & $2.19 \pm 0.17^{\mathrm{C}, \mathrm{ab}}$ \\
\hline After step 6: Sanitizer & $2.54 \pm 0.06^{\mathrm{C}, \mathrm{a}}$ & $1.82 \pm 0.12^{\mathrm{B}, \mathrm{b}}$ & $2.14 \pm 0.19^{\mathrm{C}, \mathrm{ab}}$ \\
\hline
\end{tabular}


showed a clear surface with no soiling (Figure 1A). For UF permeate-fouled membranes, biofilm development began with clumping of bacteria, followed by colonization and adherence to the membrane surface. The cells were covered with more soil and an uneven film of the foulant, possibly extracellular polymeric substance. A rough surface with some protrusions was observed on the film (Figure 1B). Extracellular polymeric substance is thought to play an important part in altering membrane surface characteristics over time, creating conditions appropriate for bacterial attachment (Mahendran et al., 2010). The overall arrangement of the cells on UF permeate biofilm was random, with few cluster-like structures and many monolayers of rods connected by extracellular polymeric substance. These bacteria were viable and deposited in large numbers (5.39 logs $\mathrm{cfu} /$ $\mathrm{cm}^{2}$ ).

Figure 1C reveals that the whey-fouled membranes differed from the UF permeate biofilms. A fine net-

\section{(A) Virgin RO membrane}

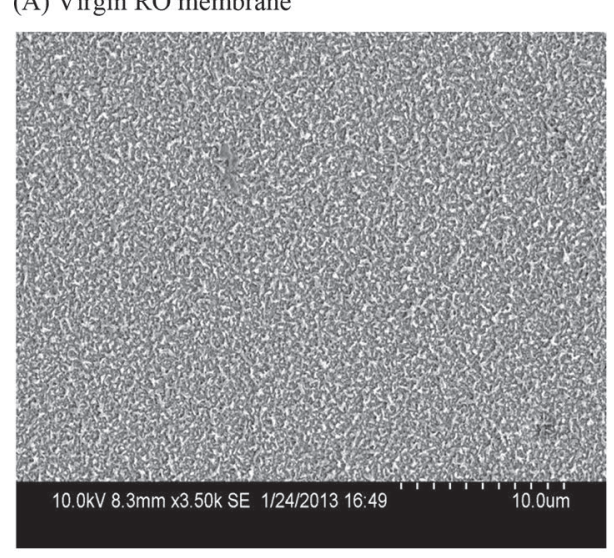

(B) UF permeate fouled membrane 48-h-old biofilms

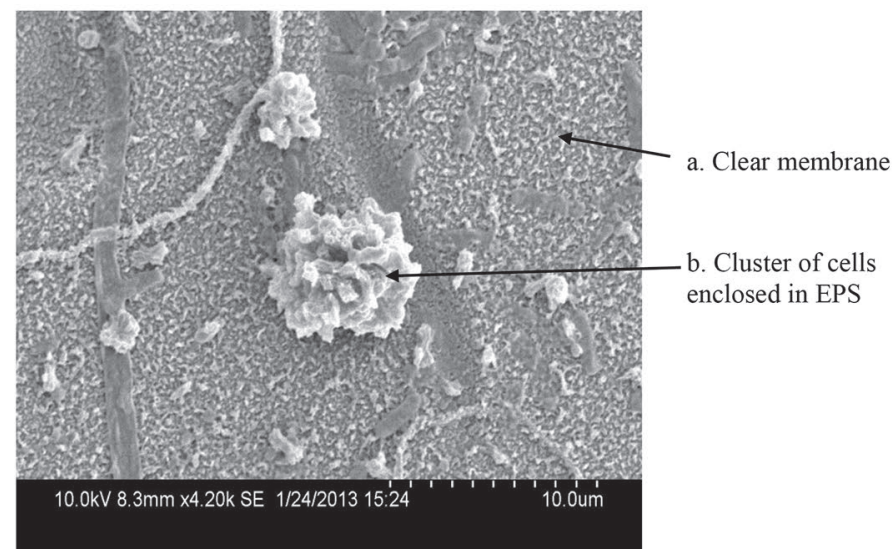

work of monolayer rods adhered to each other and the membrane, which was covered by a thin film of foulant. The whey-fouled membranes showed a very smooth surface with no protrusions on the film. The attached cells were arranged in longer chains of rods with mostly scattered groups of adherent cells. The surface of the membrane was covered with less soil and mostly clear spaces. Some studies have reported that extracellular polymeric substance furnishes a deeply hydrated gel matrix, in which bacteria are enclosed, contributing considerable resistance to cleaning and cross-flow in membranes (Mahendran et al., 2010).

The alternating whey/UF permeate-fouled biofilms were very different from the other 2 biofilms (Figure 1D). Heavily deposited clusters of biofouling were observed on the membrane, which did not cover the sheet-like material uniformly. There were micro-colony formations, with several rod-shaped bacteria trapped in these multi-layers of foulant and some soil-like mate-
(C) Whey fouled membrane 48-h-old biofilms

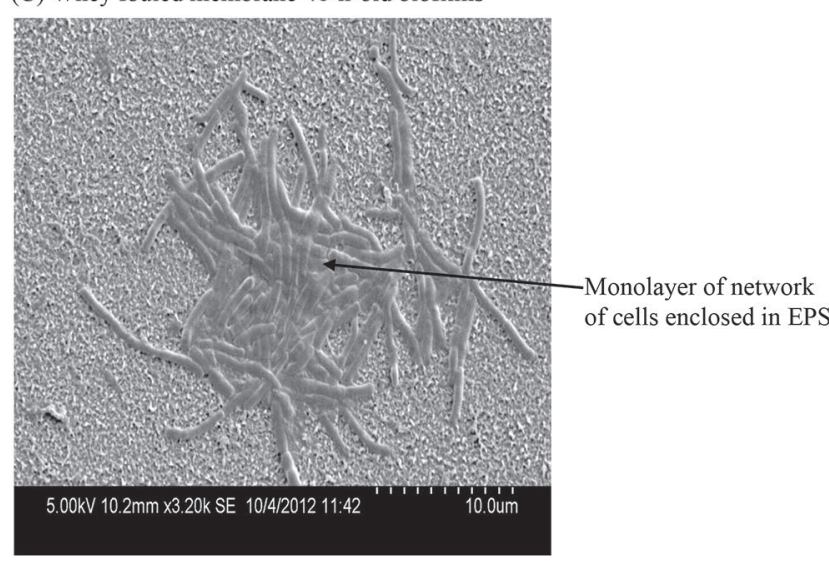

(D) Whey + UF permeate fouled membrane 48-h-old biofilms

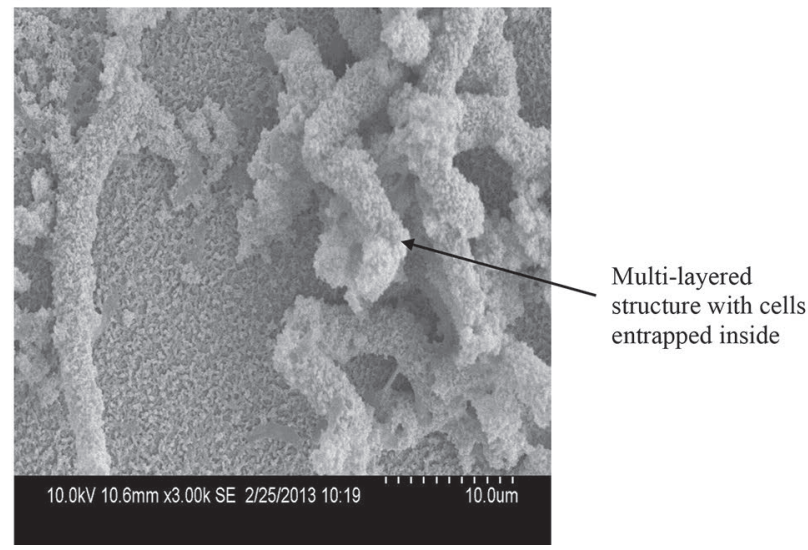

Figure 1. Scanning electron micrographs of reverse osmosis (RO) membrane surfaces at 5 to $10 \mathrm{kV}$ : (A) virgin RO membrane, (B) UF permeate-fouled membrane 48-h-old biofilm, (C) whey-fouled membrane 48-h-old biofilm (EPS = extracellular polymeric substance), and (D) alternating whey/UF permeate-fouled membrane 48-h-old biofilm. 
rial. We assume that this could be due to an interaction of the 2 feed substrates that helps the bacteria to grow in these patterns. The uneven surface of the biofouling deposits and bridges between them signify the possible presence of extracellular polymeric substance, which acts as a binding agent and holds bacterial cells together (Hassan et al., 2010).

Microscopic analysis showed that alternating whey/ UF permeate biofilms were more fouled with soiling and microorganisms than the other 2 biofilms. The microstructural difference in biofilms also suggests a difference in their resistance to cleaning processes. The results are similar to some previous findings, which indicated that different nutrient pools resulted in distinctive patterns of initial colonization and possibly structure, in the development of biofilms on membranes (Ivnitsky et al., 2007).

\section{Atomic Force Microscopy of Biofilms}

Atomic force microscopy was used to analyze feature height distribution (the height of the features, in order to compare topography) of clean and fouled membranes at the nano-scale to validate the distinct biofilm arrangement and formations caused by feed substrate characteristics. The AFM 3D and 2D images of clean polyamide RO membrane and fouled RO with UF, whey, and alternating whey/UF feed substrates are shown in Figures 2, 3, 4, and 5, respectively. Each image outlines an area of $20 \times 20 \mu \mathrm{m}$ (panel A of each figure) or $10 \times 10 \mu \mathrm{m}$ (panel B), with each image having a bar at the right side indicating vertical deviations of the sample with peaks and valleys for light and dark. Similar depictions were reported by Kwak et al. (1999).
The surface of the virgin membrane was observed to be rough, having peak-and-valley morphology with an $\mathrm{S}_{\mathrm{q}}$ value of $50.7 \mathrm{~nm}$. Previous researchers have also found polyamide membranes to be much rougher than cellulose acetate membranes $\left(\mathrm{S}_{\mathrm{q}}=6.2-6.6 \mathrm{~nm}\right.$; Zaky et al., 2012; Fang and Duranceau, 2013). The initial microbial attachment to the membrane surface is primarily due to the membrane's surface properties, which affect the strength and speed of cell adhesion to the membrane followed by multiplication and the consumption of feed substrate nutrients (Pasmore et al., 2001; Kang et al., 2006). The computed roughness and skewness values of these membranes are given in Table 3 . The roughness $\left(\mathrm{S}_{\mathrm{q}}\right)$ value of UF permeate-fouled membrane $\left(\mathrm{S}_{\mathrm{q}}=275 \mathrm{~nm}\right)$ was greater than that of membranes fouled with whey or whey/UF permeate feed $\left(\mathrm{S}_{\mathrm{q}}=96\right.$ and $103 \mathrm{~nm}$, respectively). Based on these findings, we can conclude that the UF permeate-fouled membranes were rough, so they were the hardest to clean of the 3 fouled membrane types. This is in agreement with previous studies (Vrijenhoek et al., 2001; Lee et al., 2005; Tansel et al., 2006), which showed that the decline in flux would be more extreme in membranes with greater surface roughness because clogging would result from accumulation of suspended particles in the valleys. Membrane surfaces with areas of reduced shear force would be created because of the reduction in consistent flow distribution with increasing roughness, allowing microbial cells and other feed particles to adhere to the surface.

The distributions of membrane peaks along with the height of the peaks of different biofilms were further compared in Figure 6. The unused (virgin) membrane served as a baseline (control) for comparison. Figure

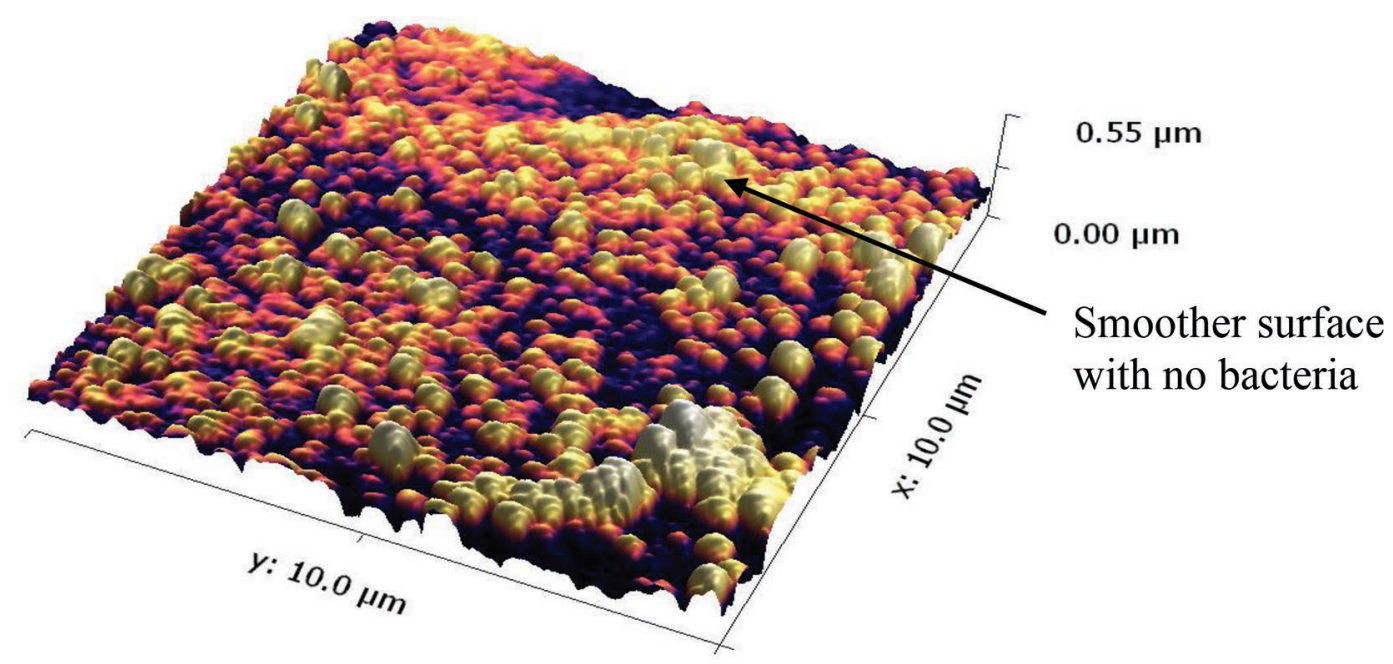

Figure 2. Atomic force microscopy 3-dimensional image of surface roughness properties of polyamide reverse osmosis (RO) virgin membrane surface showing smooth topography. Color version available online. 
(A) 3D image of UF permeate biofilm showing more peaks than valleys and very rough topography

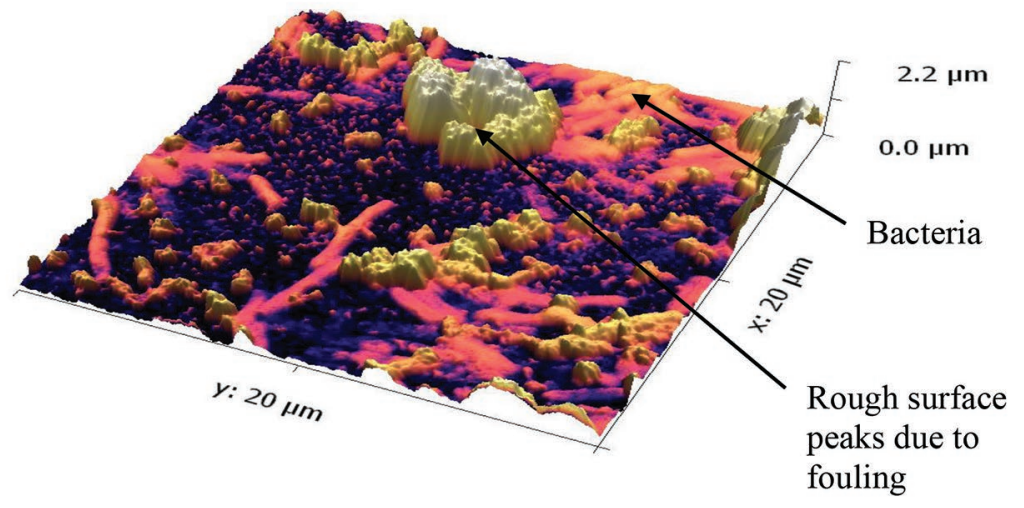

(B) 2D image of UF permeate biofilm

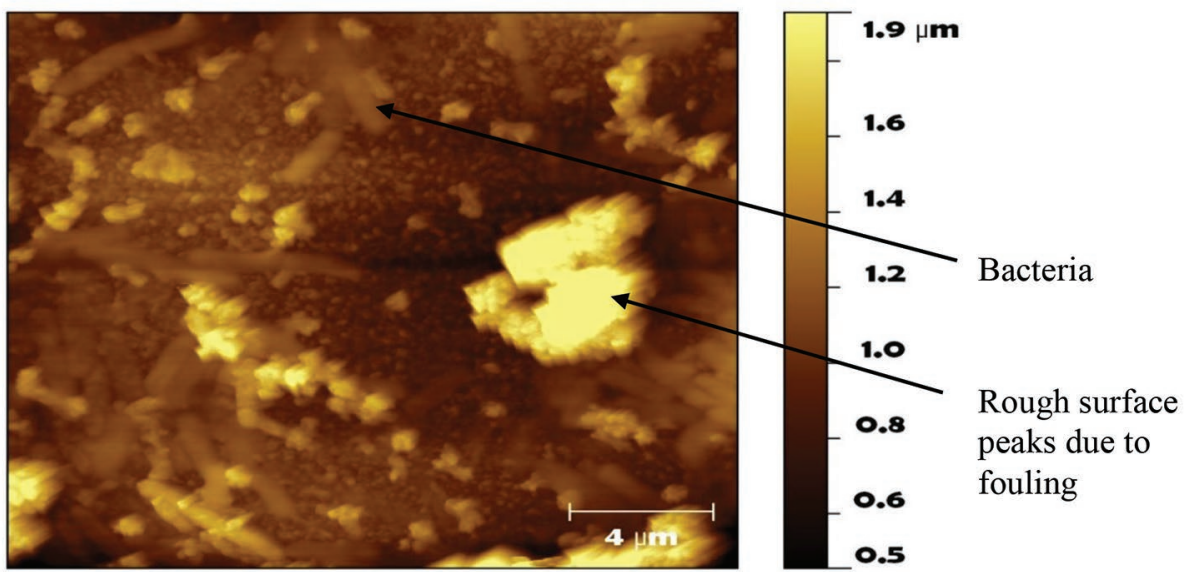

Figure 3. Atomic force microscopy 3-dimensional (3D) and 2-dimensional (2D) images of surface roughness properties of reverse osmosis (RO) membrane fouled with UF permeate: (A) 3D image of UF permeate biofilm showing more peaks than valleys and very rough topography; (B) 2D image of UF permeate biofilm. Color version available online.

6 shows that the control (clean) membrane peak distribution with least variability having similar heights. The UF permeate biofilms had a wider distribution of peaks with varying heights, and whey biofilms showed a narrower distribution of peaks compared with the UF and whey/UF permeate biofilms. This result provided further evidence that the UF permeate biofilms had the most uneven surface and were the hardest to clean.

Surface skewness $\left(\mathrm{S}_{\mathrm{sk}}\right)$ was evaluated to observe the uniformity of the biofilms. The clean membrane, whey, and whey/UF fouled membrane biofilms were closer to uniformity $\left(\mathrm{S}_{\mathrm{sk}}=0\right)$ than the UF-fouled membranes. The UF permeate biofilms, whey/UF biofilms, and the virgin membrane had positive $S_{\mathrm{sk}}$ values, indicating their surfaces had more peaks than valleys. The wheyfouled membrane had a negative $S_{\text {sk }}$ value $\left(S_{\text {sk }}=-0.04\right)$, indicating more valleys than peaks. The intensity of bacterial colonization appeared to increase as surface roughness increased. This implies that microbial cells are highly inclined to accumulate and develop a stronger biofilm on the UF permeate-fouled membranes than on the others tested in this study.

\section{CONCLUSIONS}

This study provided important information related to the differences in microstructure and cleaning resistance of biofilms formed from different feed substrates commonly processed in the dairy industry. As membrane processing extended from 24 to $48 \mathrm{~h}$, viable counts increased in biofilms formed by UF permeate, whey, and an alternating whey/UF combination. The UF permeate feed helped the embedded bacterial biofilm to grow to higher numbers compared with the other feed substrates. The UF permeate biofilms showed the greatest resistance to cleaning. Scanning electron 
micrographs showed differences in the microstructures of all the biofilms. The alternating whey/UF permeate biofilm showed the most soiling, with multilayering of many cells. The AFM image analysis indicated that UF permeate biofilms had the roughest surfaces, with more peaks than other biofilms, and confirmed the biofilm cleaning results indicating that UF permeate biofilms were the most resistant biofilms and hardest to clean. Based on our results, one type of CIP protocol may not be applicable for all types of biofilms formed by different RO feed substrates. We are conducting further studies on the modification of the existing CIP protocol and to optimize it depending on the type of biofilms and their cleanability.

\section{(A) 3D image of whey biofilm showing more valleys}

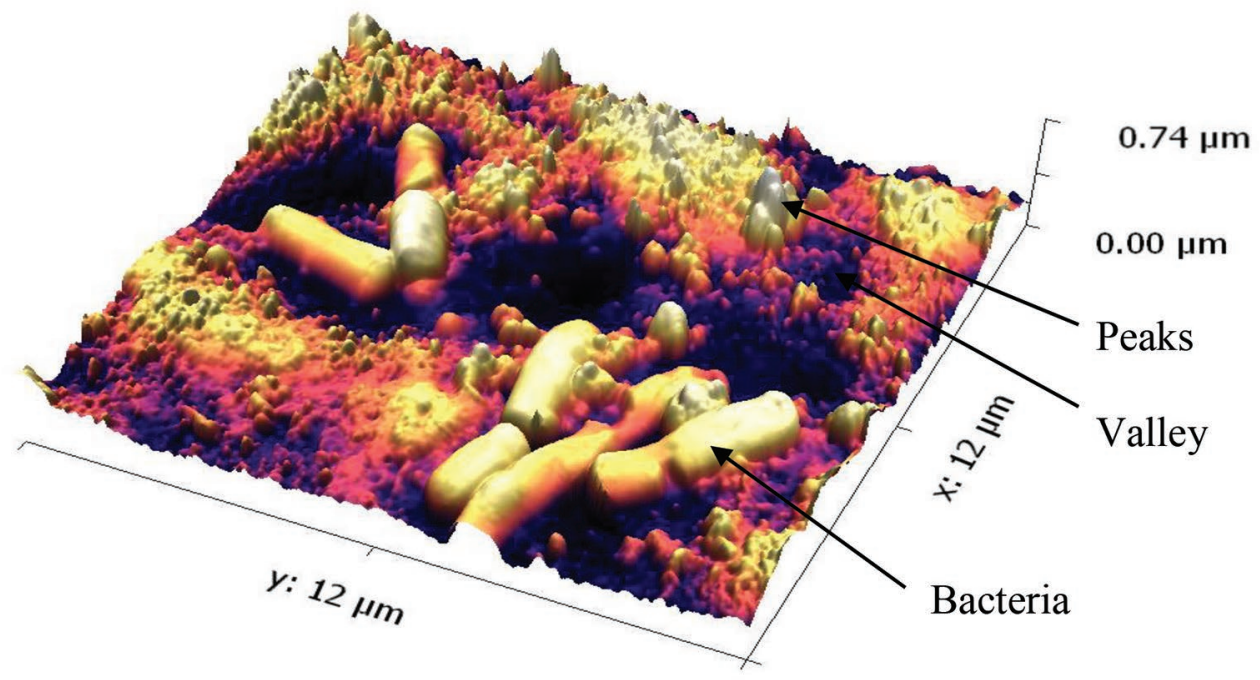

(B) 2D whey biofilm image

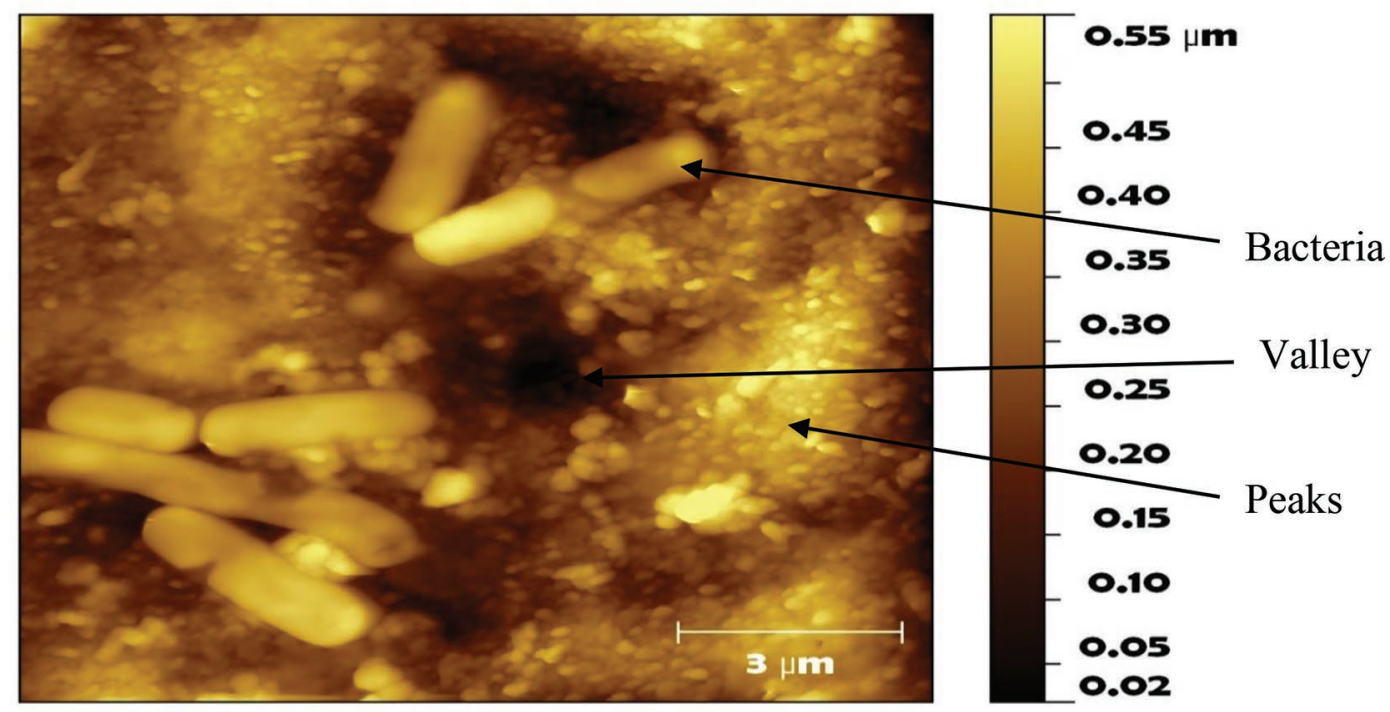

Figure 4. Atomic force microscopy 3-dimensional (3D) and 2-dimensional (2D) images of surface roughness properties of reverse osmosis (RO) membrane fouled with whey: (A) 3D image of whey biofilm showing more valleys, and (B) 2D whey biofilm image. Color version available online. 
Table 3. Computed roughness $\left(\mathrm{S}_{\mathrm{q}}\right)$ and skewness $\left(\mathrm{S}_{\mathrm{sk}}\right)$ of clean (virgin) membrane and 48-h-old membrane biofilms ${ }^{1}$

\begin{tabular}{lcccc}
\hline Parameter & Virgin membrane & UF & Whey & Whey/UF \\
\hline $\mathrm{S}_{\mathrm{q}}(\mathrm{nm})$ & 50.7 & 275 & 96 & 103 \\
$\mathrm{~S}_{\mathrm{sk}}$ & 0.68 & 1.98 & -0.04 & 0.73 \\
\hline
\end{tabular}

${ }^{1}$ Membranes were subjected to reverse osmosis using feed substrates of UF permeate, whey permeate, or alternating whey/UF permeate.

\section{(A) 3D image of whey + UF permeate biofilm showing rougher surface topography}

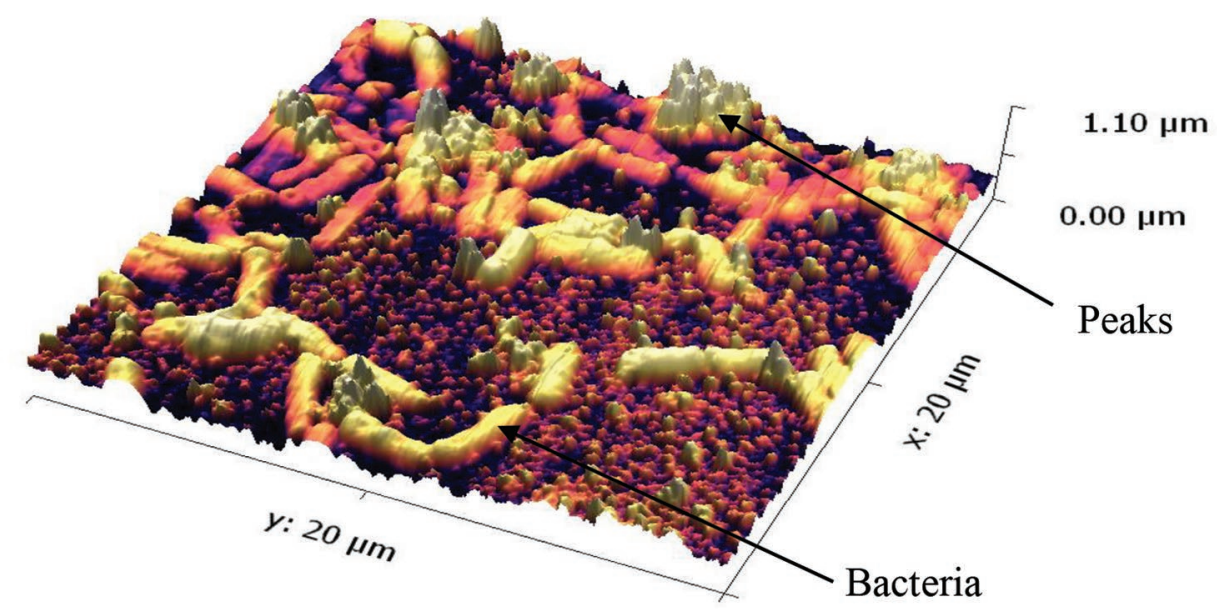

(B) 2D image of whey + UF permeate biofilm

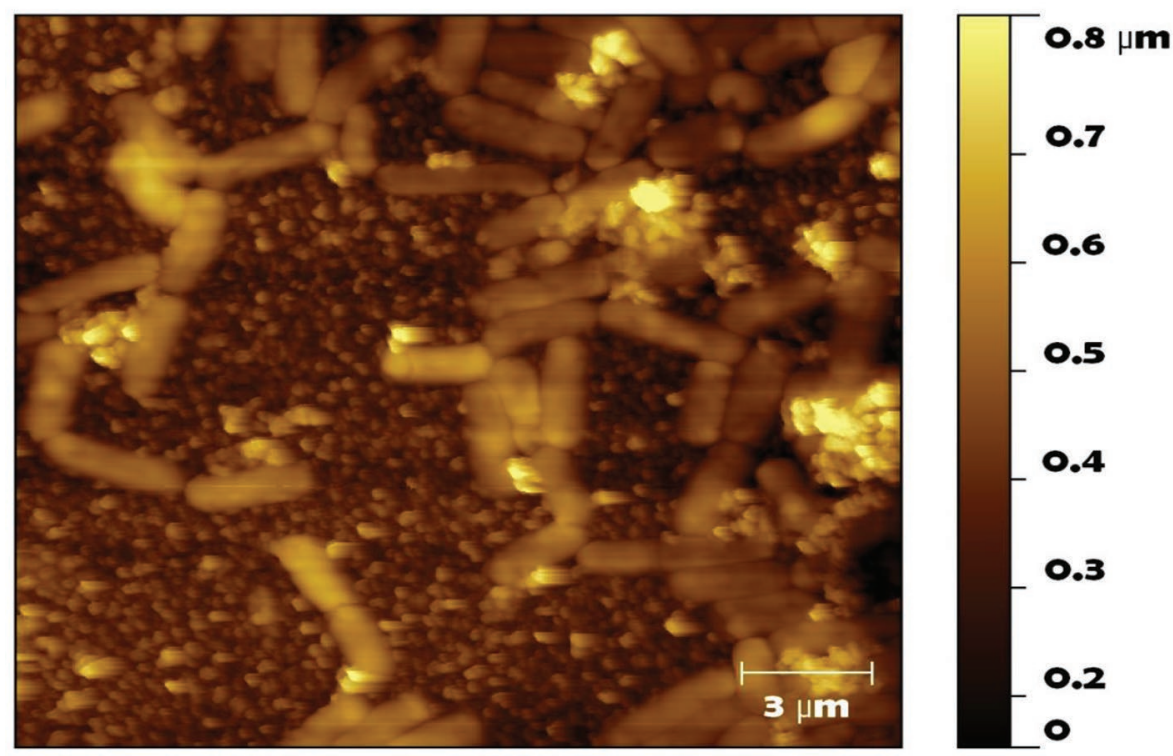

Figure 5. Atomic force microscopy 3-dimensional (3D) and 2-dimensional (2D) images of surface roughness properties of reverse osmosis (RO) membrane fouled with alternating whey/UF permeate: (A) 3D image of whey/UF permeate biofilm showing rougher surface topography, and (B) 2D image of whey/UF permeate biofilm. Color version available online. 


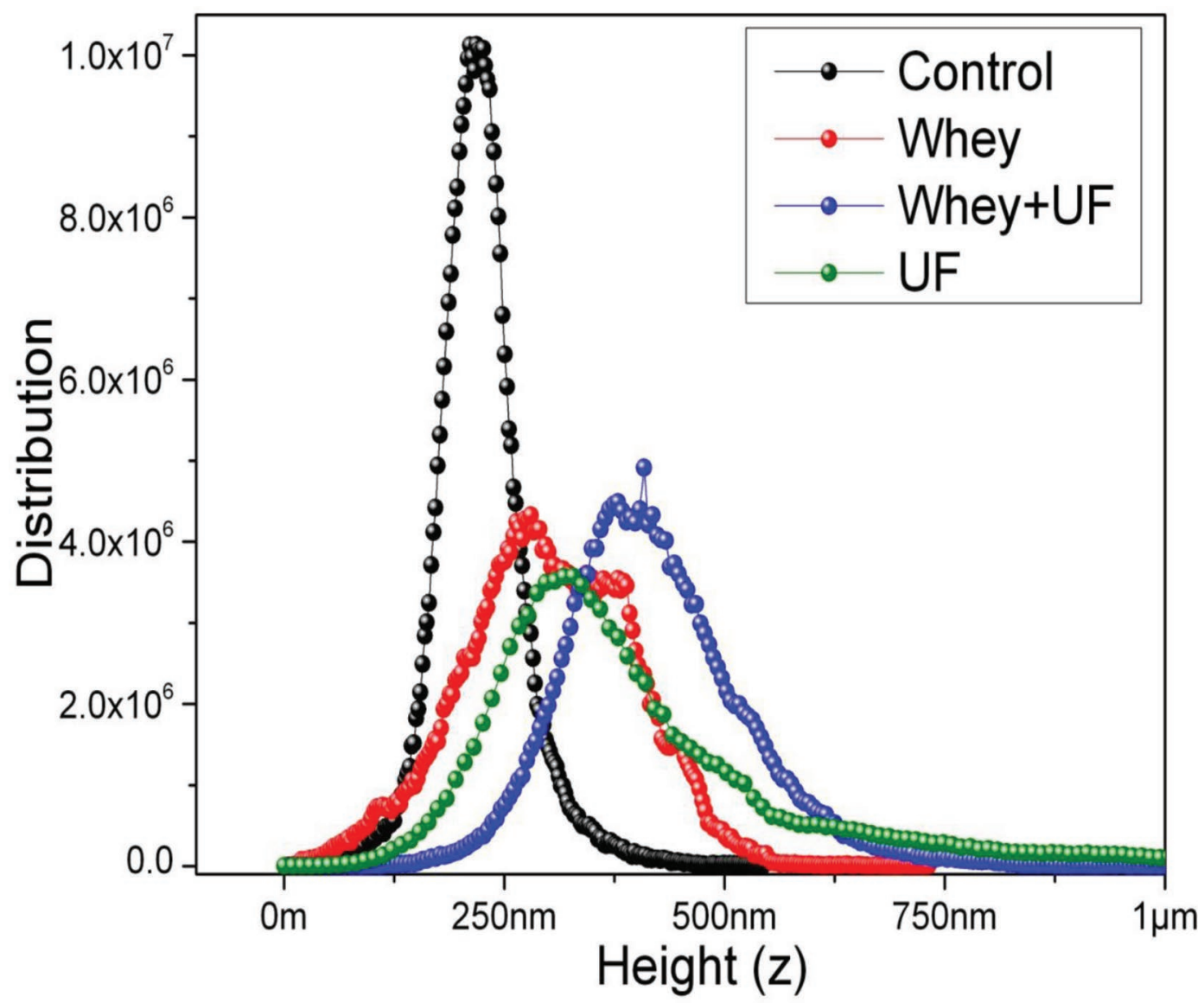

Figure 6. Atomic force microscopy analysis showing the distribution of the height of membrane peaks of different biofilms. Color version available online.

\section{ACKNOWLEDGMENTS}

The authors thank QiquanQiao, Hongshan He, Swaminathan Venkatesan, and Maheshwar Shrestha (Electrical Engineering and Computer Science Department, South Dakota State University, Brookings) for help with the atomic force and scanning electron microscopy. This work was funded by Dairy Management Inc. (DMI; Rosemont, IL), and administered by the Dairy Research Institute (DRI). The authors also acknowledge the support of Agricultural Experimentation Station (South Dakota State University, Brookings) in conducting the study.

\section{REFERENCES}

Anand, S., and D. Singh. 2013. Resistance of the constitutive microflora of biofilms formed on whey reverse-osmosis membranes to individual cleaning steps of a typical clean-in-place protocol. J. Dairy Sci. 96:6213-6222.

Asséré, A., N. Oulahal, and B. Carpentier. 2008. Comparative evaluation of methods for counting surviving biofilm cells adhering to a polyvinyl chloride surface exposed to chlorine or drying. J. Appl. Microbiol. 104:1692-1702.
Bereschenko, L. A., G. Heilig, M. Nederlof, M. Van Loosdrecht, A Stams, and G. Euverink. 2008. Molecular characterization of the bacterial communities in the different compartments of a full-scale reverse-osmosis water purification plant. Appl. Environ. Microbiol. 74:5297-5304.

Bereschenko, L. A., A. Stams, G. Euverink, and M. van Loosdrecht. 2010. Biofilm formation on reverse osmosis membranes is initiated and dominated by Sphingomonas spp. Appl. Environ. Microbiol. 76:2623-2632.

De Wit, J. 2001. Lecturer's Handbook on Whey and Whey Products. European Whey Products Association, Brussels, Belgium.

Donlan, R. M. 2002. Biofilms: Microbial life on surfaces. Emerg. Infect. Dis. 8:881-890.

Fang, Y., and S. J. Duranceau. 2013. Study of the effect of nanoparticles and surface morphology on reverse osmosis and nanofiltration membrane productivity. Membranes 3:196-225.

González, J. E., and N. D. Keshavan. 2006. Messing with bacterial quorum sensing. Microbiol. Mol. Biol. Rev. 70:859-875.

Hassan, A. N., S. Anand, and M. Avadhanula. 2010. Microscopic observation of multispecies biofilm of various structures on whey concentration membranes. J. Dairy Sci. 93:2321-2329.

Ivnitsky, H., I. Katz, D. Minz, G. Volvovic, E. Shimoni, E. Kesselman, R. Semiat, and C. G. Dosoretz. 2007. Bacterial community composition and structure of biofilms developing on nanofiltration membranes applied to wastewater treatment. Water Res. 41:3924-3935.

Kang, S., E. M. Hoek, H. Choi, and H. Shin. 2006. Effect of membrane surface properties during the fast evaluation of cell attachment. Sep. Sci. Technol. 41:1475-1487. 
Kwak, S. Y., S. G. Jung, Y. S. Yoon, and D. W. Ihm. 1999. Details of surface features in aromatic polyamide reverse osmosis membranes characterized by scanning electron and atomic force microscopy. J. Polym. Sci., B, Polym. Phys. 37:1429-1440.

Lee, N., G. Amy, J.-P. Croué, and H. Buisson. 2005. Morphological analyses of natural organic matter (NOM) fouling of low-pressure membranes (MF/UF). J. Membr. Sci. 261:7-16.

Lipnizki, F. 2010. Cross-flow membrane applications in the food industry. Membr. Technol. Membr. Food Applic. 3:1-24.

Lu, Z., L. Meng, Z. Liu, G. Ren, A. Sun, and X. Liu. 2013. Expression of quorum-sensing related genes during Enterococcus faecalis biofilm formation. Zhonghua kouqiang yixue zazhi 48:485-489.

Lund, D. B., E. Plett, and C. Sandu, ed. 1985. Fouling and cleaning in food processing. In Proc. 2nd Int. Conf. Fouling and Cleaning in Food Processing, Madison, WI. University of Wisconsin, Madison.

Madaeni, S., and Y. Mansourpanah. 2004. Chemical cleaning of reverse osmosis membranes fouled by whey. Desalination 161:13-24.

Madaeni, S., and S. Samieirad. 2010. Chemical cleaning of reverse osmosis membrane fouled by wastewater. Desalination 257:80-86.

Mahendran, B., H. Lin, B. Liao, and S. N. Liss. 2010. Surface properties of biofouled membranes from a submerged anaerobic membrane bioreactor after cleaning. J. Environ. Eng. 137:504-513.

Nguyen, T., F. A. Roddick, and L. Fan. 2012. Biofouling of water treatment membranes: A review of the underlying causes, monitoring techniques and control measures. Membranes 2:804-840.

Pabby, A. K., S. S. Rizvi, and A. M. Sastre. 2008. Handbook of Membrane Separations: Chemical, Pharmaceutical, Food, and Biotechnological Applications. CRC Press, Boca Raton, FL.

Pasmore, M., P. Todd, S. Smith, D. Baker, J. Silverstein, D. Coons, and C. N. Bowman. 2001. Effects of ultrafiltration membrane surface properties on Pseudomonas aeruginosa biofilm initiation for the purpose of reducing biofouling. J. Membr. Sci. 194:15-32.

Raposo, M., Q. Ferreira, and P. Ribeiro. 2007. A guide for atomic force microscopy analysis of soft-condensed matter. Modern Res. Educ. Top. Microsc. 1:758-769.

Rice, A. R., M. A. Hamilton, and A. K. Camper. 2000. Apparent surface associated lag time in growth of primary biofilm cells. Microb. Ecol. 40:8-15.
Robinson, R. K. 1986. Modern Dairy Technology: Advances in Milk Processing. Elsevier Applied Science Publishers. Philadelphia, PA.

Siegerman, H., W. Hollands, and M. Strauss. 2006. Optimum swabbing techniques for cleaning validation. How to succeed in the search for nothing: Effective swabbing techniques for cleaning validation, vol. 1. Accessed Oct. 25, 2017. http://www.cemag.us/ articles /2007/02/how-succeed-search-nothing-effective-swabbing -techniques-cleaning-validation.

Tang, X., S. Flint, R. Bennett, and J. Brooks. 2010. The efficacy of different cleaners and sanitisers in cleaning biofilms on UF membranes used in the dairy industry. J. Membr. Sci. 352:71-75.

Tansel, B., J. Sager, J. Garland, S. Xu, L. Levine, and P. Bisbee. 2006. Deposition of extracellular polymeric substances (EPS) and microtopographical changes on membrane surfaces during intermittent filtration conditions. J. Membr. Sci. 285:225-231.

Tsakali, E., K. Petrotos, A. D'Allessandro, and P. Goulas. 2010. A review on whey composition and the methods used for its utilization for food and pharmaceutical products. In Proc. 6th Int. Conf. Simulation and Modelling in the Food and Biol.-Industry (FOODSIM 2010). June 24-26. CIMO, Braganca, Portugal.

Venkatesan, S., N. Adhikari, J. Chen, E. C. Ngo, A. Dubey, D. W. Galipeau, and Q. Qiao. 2014. Interplay of nanoscale domain purity and size on charge transport and recombination dynamics in polymer solar cells. Nanoscale 6:1011-1019.

Vrijenhoek, E. M., S. Hong, and M. Elimelech. 2001. Influence of membrane surface properties on initial rate of colloidal fouling of reverse osmosis and nanofiltration membranes. J. Membr. Sci. 188:115-128.

Yang, P., K. Burson, D. Feder, and F. Macdonald. 2005. Swab Sampling for Cleaning Validation. Pharmaceutical Technology. 1:8494.

Zaky, A. M., I. C. Escobar, and C. L. Gruden. 2012. Application of atomic force microscopy for characterizing membrane biofouling in the micrometer and nanometer scales. Environ. Prog. Sustain. Energy 32:449-457. 